\title{
MOBILITY OF EXTRAJUNCTIONAL ACETYLCHOLINE RECEPTORS ON DENERVATED ADULT MUSCLE FIBERS ${ }^{1}$
}

\author{
M. STYA AND D. AXELROD \\ Biophysics Research Division, Institution of Science and Technology, The University of Michigan, Ann Arbor, Michigan 48109
}

Received March 17, 1983; Revised June 20, 1983; Accepted June 27, 1983

\begin{abstract}
We report the lateral mobility of extrajunctional acetylcholine receptors (AChR), marked with fluorescently labeled $\alpha$-bungarotoxin, on rat flexor digitorum brevis single muscle fibers maintained in cell culture. Mobility is measured by a modification of the fluorescence photobleaching recovery technique. The denervated rat flexor digitorum brevis muscle fibers exhibit a nonuniform distribution of AChR on their sarcolemmas. Diffusely distributed $\mathrm{AChR}$ have an average diffusion coefficient of about $2.5 \times 10^{-11} \mathrm{~cm}^{2} / \mathrm{sec}$, somewhat lower than that of diffusely distributed AChR on embryonic rat myotubes in culture. Extrajunctional AChR aggregated into small clusters $(<20 \mu \mathrm{m})$ have an average diffusion coefficient of about $5 \times 10^{-12} \mathrm{~cm}^{2} / \mathrm{sec}$. Both the clustered and nonclustered extrajunctional AChR have lateral mobilities several orders of magnitude greater than that of junctional AChR.
\end{abstract}

In normally innervated adult muscle fibers, acetylcholine receptors $(\mathrm{AChR})$ are densely packed at the myoneural junction and arc restricted to that region. These junctional AChR are known to be essentially immobile (Axelrod et al., 1976a, b; Fambrough and Pagano, 1977).

Upon denervation, however, muscle fibers gradually become sensitive to acetylcholine ( $\mathrm{ACh}$ ) along their entire length. Although this phenomezon has been called "spread of sensitivity," it is not due to mobilization and subsequent lateral diffusion of junctional AChR, but rather to the insertion of newly synthesized receptors into extrajunctional regions of the cell membrane (Brockes and Hall, 1976; Devreotes and Fambrough, 1976). The junctional receptors remain densely packed, and presumably immobile, at the motor endplates; the mobility of the extrajunctional receptors has not been measured previously. We report here results of fluorescence photobleaching recovery experiments which indicate that, unlike the immobile junctional AChR, extrajunctional AChR are capable of lateral diffusion. Denervated muscle fibers do not exhibit a uniform distribution of extrajunctional AChR. Some of these receptors are aggregated in small $(<10 \mu \mathrm{m})$ clusters (Bekoff and Betz,

\footnotetext{
${ }^{1}$ We are grateful to $R$. Bischoff for demonstrating his techniques for the dissection and plating of adult muscle fibers. We thank $\mathrm{K}$. Barald, J. Jay, and D. Grega for their help in adapting these techniques to our laboratory and for many helpful discussions. We thank C. M. Stya for plating the myotubes and Deborah Rapley for typing the manuscript. This work was supported by National Institutes of Heatlh Grants NS14565 and NDS17017 to D. A.
}

1977; Ko et al., 1977; 'lipnis and Malhotra, 1979). We report that the receptors within the extrajunctional clusters are less mobile than the diffusely distributed extrajunctional AChR although their mobility still exceeds that of the junctional receptors by several orders of magnitude.

\section{Materials and Methods}

Formulations of buffers and medium. Modified Puck's 5X (MP 5X) was prepared by adding $3.60 \mathrm{gm}$ of $\mathrm{NaCl}$, $0.20 \mathrm{gm}$ of $\mathrm{KCl}, 0.68 \mathrm{gm}$ of $\mathrm{NaHPO}_{4}$, and $0.10 \mathrm{gm}$ of $\mathrm{NaH}_{2} \mathrm{PO}_{4} \cdot \mathrm{H}_{2} \mathrm{O}$ to $100 \mathrm{ml}$ of $\mathrm{H}_{2}$. From this $\mathrm{MP}^{2} \mathrm{Ca}^{2+}$ and $\mathrm{Mp}-\mathrm{Mg}^{2+}$ were prepared as follows: $20 \mathrm{ml}$ of MP $5 \mathrm{X}$, $75 \mathrm{ml}$ of $\mathrm{H}_{2} \mathrm{O}, 1 \mathrm{ml}$ of $10 \%$ glucose, and $1 \mathrm{ml}$ of either $0.18 \mathrm{M} \mathrm{CaCl}_{2}\left(\mathrm{MP}-\mathrm{Ca}^{2+}\right)$ or $0.081 \mathrm{M} \mathrm{MgSO}_{4}\left(\mathrm{MP}-\mathrm{Mg}^{2+}\right)$. The latter ingredient should be added dropwise while stirring. PBS/glu consisted of $200 \mathrm{ml}$ of phosphatebuffered saline (PBS), $20 \mathrm{ml}$ of $10 \%$ glucose, $0.25 \mathrm{ml}$ of phenol red, $2 \mathrm{ml}$ of $\mathrm{MP}-\mathrm{Ca}^{2+}$, and $2 \mathrm{ml}$ of $\mathrm{MP}-\mathrm{Mg}^{2+}$ brought to $\mathrm{pH}$ 7.4. The latter ingredient should be added last and dropwise while stirring to prevent precipitation.

The cells were plated in Vitrogen gel: $2 \mathrm{ml}$ of Vitrogen 100 (Flow Laboratories), $0.25 \mathrm{ml}$ of minimal essential medium (MEM) with Earle's salts (Grand Island Biological Co.) (GIBCO)), $0.10 \mathrm{ml}$ of $0.14 \mathrm{M} \mathrm{NaOH}$, and 0.08 $\mathrm{ml}$ of $7.5 \% \mathrm{NaHCO}_{3}$. The gel was mixed on ice just before use and was kept chilled.

The cells were maintained in medium C: Dulbecco's MEM (GIBCO) with $10 \%$ horse serum (M.A. Bioproducts), L-glutamine $(0.29 \mathrm{mg} / \mathrm{ml})$ (GIBCO), penicillin $(500$ 
units $/ \mathrm{ml}$ ), and streptomycin $(500 \mathrm{mg} / \mathrm{ml}$ ) (as penicillinstreptomycin solution from GIBCO).

Preparation of muscle fibers. Methods of muscle isolation were described by Bekoff and Betz (1977) as well as by Bischoff (1980). The modified technique described here is by Bischoff (private communication). The flexor digitorum brevis muscles (FDB) were dissected from the plantar aspects of the hindfeet of 150 - to 200 -gm rats and were placed in a dish containing PBS/glu (see 'Formulations of Buffers and Medium") where they were cleaned of as much connective tissue as possible. The cleaned muscles were incubated in PBS/glu containing $0.2 \%$ collagenase (Sigma, type I) for 1 to $1 \frac{1}{2} \mathrm{hr}$ with occasional gentle agitation. The muscles were then washed several times with medium C (see "Formulations of Buffers and Medium"), the tendons were gently pulled apart with watchmaker forceps, and the resulting clumps were triturated several times through a wide-mouthed pipette. The fibers were allowed to settle for 5 to $7 \mathrm{~min}$, the supernatant was drawn off and discarded, and fresh medium was added. The supernatant contains mainly debris and non-muscle cells which, being less dense than the muscle fibers, settle more slowly. This trituration procedure was repeated four times in an attempt to minimize the population of undesirable cells. Following the last trituration the remaining clumps were removed, and the single muscle fibers were allowed to settle for 30 min. Culture dishes were prepared by placing 1 drop of the Vitrogen gel (see "Formulations of Buffers and Medium") on alcohol-cleaned glass-bottomed culture dishes (32.5 $\mathrm{mm}$ in diameter) and spreading it carefully to the edges. The dishes were incubated at $37^{\circ} \mathrm{C}$ in a $10 \% \mathrm{CO}_{2}$ water-saturated environment for 15 to $20 \mathrm{~min}$ to allow gelling. The settled single muscle fibers in medium were placed on ice, as much supernatant as possible was drawn off, and the fibers were mixed 1:1 with Vitrogen gel. The gel-cell mixtures was plated on the prepared dishes by placing 1 drop of the mixture on each dish. The dishes were returned to the incubator for 15 to $30 \mathrm{~min}$ to allow gelling and were subsequently covered with a layer of Vitrogen gel ( $\sim 3$ drops/dish). Finally, the dishes were incubated for 45 to $60 \mathrm{~min}$ (to allow gelling) before being fed by careful dropwise addition of $3-\mathrm{ml}$ volumes of medium C. Medium was changed daily. Experiments on junctional AChR were carried out on the day of plating; all other experiments were performed on day 14 after plating. By this time only a small fraction of the fibers was still living and attached to the substrate.

Preparation of primary muscle cultures. Cultures were prepared as described previously (Axelrod, 1981) and were plated on glass-bottomed culture dishes in medium containing $10 \%$ fetal bovine serum and $0.6 \mu \mathrm{g}$ tetrodotoxin/ml (TTX, obtained from Sigma). Medium was changed every other day. The experiments were performed on 7-day-old cultures.

Fluorescent toxins. Tetramethylrhodamine $\alpha$-bungarotoxin (R-BT) was prepared according to the method described by Ravdin and Axelrod (1977). Muscle fibers were exposed to R-BT in medium for $1 \mathrm{hr}$ at $37^{\circ} \mathrm{C}$, were washed several times with phosphate-buffered saline (PBS, obtained from GIBCO) containing $0.6 \mu \mathrm{g}$ TTX/ $\mathrm{ml}$, and were placed in a $3-\mathrm{ml}$ volume of this PBS/TTX.
R-BT labeling is irreversible on the time scale of our experiments (Devreotes and Fambrough, 1975).

Fluorescence measurements. Fluorescence of cells was excited by the $514 \mathrm{~nm}$ line of an argon ion laser (Lexel 95.3) and viewed with an inverted microscope (Leitz Diavert) using a $\times 100$, numerical aperture $=1.20$, water immersion objective. Lateral motion of fluorescently labeled AChR was measured by a modification of the fluorescence photobleaching recovery technique (FPR; see Axelrod et al., 1976a). This modification was necessitated by the faintness of the label and takes advantage of the fact that the fluorescence is brighter at the edge of the cell since the optical path traverses more cell membrane (and hence more fluorescent label) in that region.

A cylindrical lens was used to focus the laser beam to a stripe $\left(e^{-2}\right.$ Gaussian half-width $\left.=0.35 \mu \mathrm{m}\right)$ rather than to the more conventional circular spot. The axis of the muscle fiber was oriented perpendicularly to this stripe. A rectangular aperture in the image plane of the microscope limited the gathered fluorescence to that emanating from a small region on the edge of the cell (Fig. 1). A brief $(50-\mathrm{msec})$ and intense $\left(5 \mathrm{~mW} / \mu \mathrm{m}^{2}\right)$ pulse of laser light caused irreversible photochemical bleaching of the

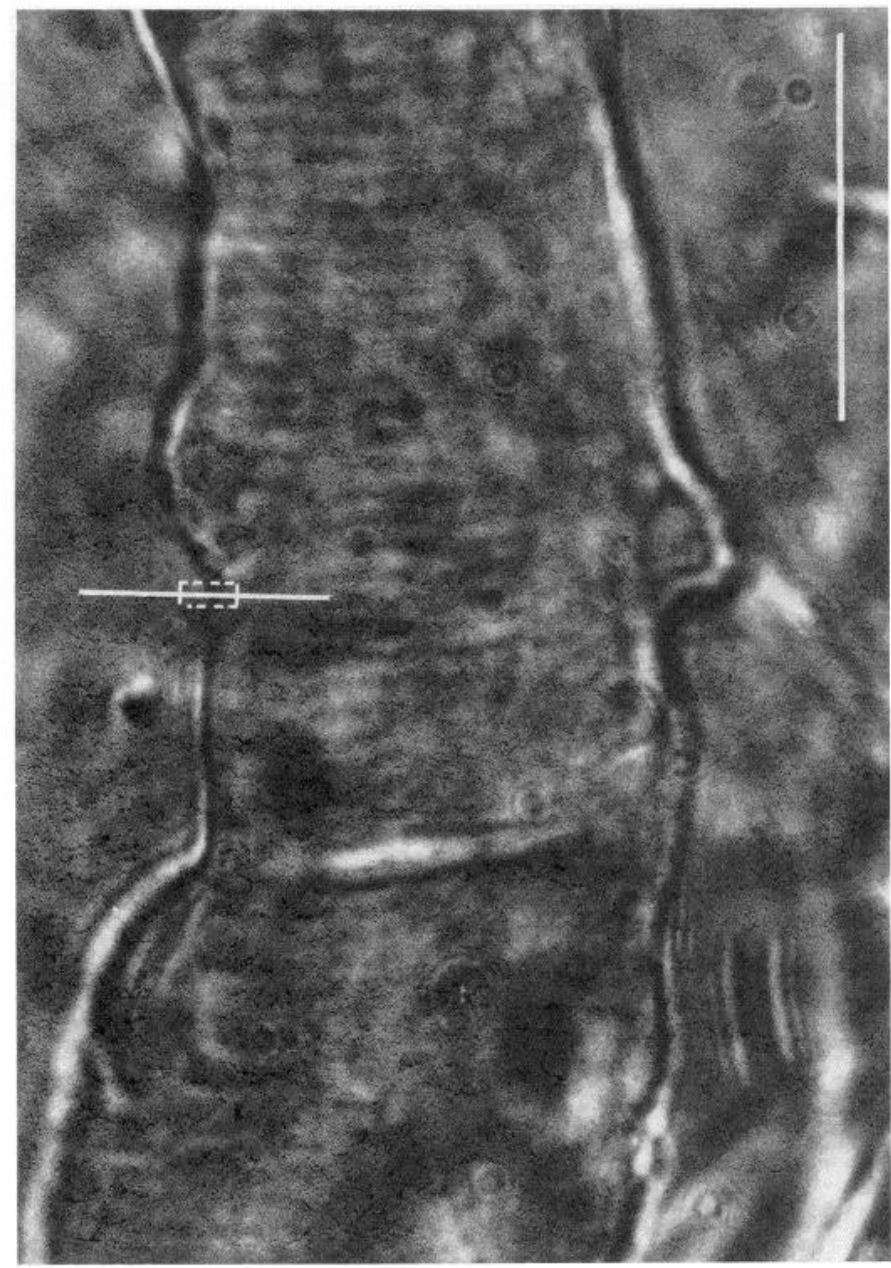

Figure 1. Spatial configuration of bleaching pattern. Horizontal line, representation of focused laser beam; dotted lines, region from which fluorescence is gathered; vertical bar, $25 \mu \mathrm{m}$. 
fluorophore in that region. The diffusion coefficient was determined from the rate of recovery of fluorescence (excited by the same laser beam attenuated $\sim 2 \times 10^{4}$ times) which results from the diffusion of unbleached fluorophore into the bleached region. Fluorescence recovery was recorded for 15 to $20 \mathrm{~min}$ following bleach.

Assuming that bleaching is an irreversible first-order process, the lateral diffusion coefficient for bleaching by a Gaussian stripe is given by;

$$
D=\frac{3 w^{2} \gamma}{4 \tau_{1 / 2}}
$$

(Feldman et al., 1981; Axelrod et al., 1976a; Stya, 1983). Factor $w$ is the $e^{-2}$ intensity half-width, $\tau_{1 / 2}$ is the time required for the half-recovery of fluorescence, and $\gamma$ (a bleaching depth correction) is 1.3 in this study. The average lateral diffusion coefficient is given by $\bar{D}=D f$, where $f$ is the fraction of fluorophores that are mobile.

The fluorescence measurements must be corrected for background fluorescence (from glass, solution, and dark count) and for autofluorescence (from the cell interior). We found the total fluorescence observed at the edge of R-BT-labeled cells to be 1.5 to 2.6 times brighter than the background fluorescence measured by identically sized areas devoid of cells. By measuring typical FPR curves on unlabeled cells at the edge and at the center (where almost all of the observed fluorescence above background is due to cell autofluorescence), the contribution of cell autofluorescence to the total fluorescence recovery at the edges of $\mathrm{R}$-BT-labeled cells could be determined and subtracted. On the average about $60 \%$ of the edge fluorescence above background on R-BTlabeled cells (in diffusely labeled areas) could be attributed to $\mathrm{R}$-BT-labeled $\mathrm{AChR}$ and the remaining $40 \%$ to autofluorescence.

The level of nonspecific R-BT binding was determined by blocking the AChR with unlabeled BT for $1 \mathrm{hr}$ before treating the cells with $\mathrm{R}$-BT for $1 \mathrm{hr}$. The resulting fluorescence was no greater than that of the cell-free background; thus, we conclude that R-BT binds specifically to the extrajunctional AChR and, moreover, that this specific labeling results in fluorescence intensity levels which are sufficiently above those of the nonspecific background to yield usable data.

The fluorescence experiments were performed at $22^{\circ} \mathrm{C}$ within about 2 to $3 \mathrm{hr}$ after the completion of labeling by R-BT. On other cell systems at $37^{\circ} \mathrm{C}$, the characteristic time for removal of $\mathrm{AChR}$ from the surface is much longer than $2 \mathrm{hr}$ (Devreotes and Fambrough, 1975; Axelrod, 1981). (Analogous turnover studies on dissociated and cultured FDB have not been published.) We therefore reasonably assume that most of the fluorescently labeled AChR remained on the cell surface during the experiments.

Lateral diffusion of $\mathrm{AChR}$ on developing Xenopus muscle has been measured (by ACh sensitivity after local blockage with $\alpha$-bungarotoxin (BT)) (Young and Poo, 1983) to be about 50 times faster than AChR diffusion on developing rat muscle as measured by FPR (Axelrod et al., 1976a), thereby raising questions about artifacts in lateral diffusion measurements. The sources of the difference are not yet clear but could include a combi- nation of the following factors: a species difference (rat versus Xenopus); some error in the estimated area of blockage by $\alpha$-BT and/or area of photobleaching by FPR; sensitivity of the techniques to different AChR populations (i.e., total $\alpha$-BT-binding receptors in FPR versus only ACh-sensitive receptors in blockage experiments); or an initial reversible binding of $\alpha$-BT which would affect blockage results but not FPR. The possibility that FRP leads to membrane photodamage cannot be excluded, but this appears not to be a problem in a number of other systems (see Jacobson et al., 1983, for a review of the evidence).

\section{Results}

The sparse distribution of extrajunctional AChR on living muscle fibers results in $\mathrm{R}-\mathrm{BT}$ labeling so faint that it can be observed only with high aperture objectives. Unlike living fibers, dead fibers show a bright autofluorescence that obscures any R-BT labeling. Living fibers also exhibit bulging nuclei along their length whereas dead ones do not.

The extrajunctional clusters of AChR are not sharply delineated (as are endogenous clusters on primary myotubes) but rather appear as speckly strips along the edge of the muscle fibers (faintness of the label precludes visualization of $\mathrm{AChR}$ anywhere but along the edge of the cells). These speckly strips are more than twice as bright as the other regions of the membrane, as determined by measurement of pre-bleach fluorescence levels.

Typical FPR curves of extrajunctional (both clustered

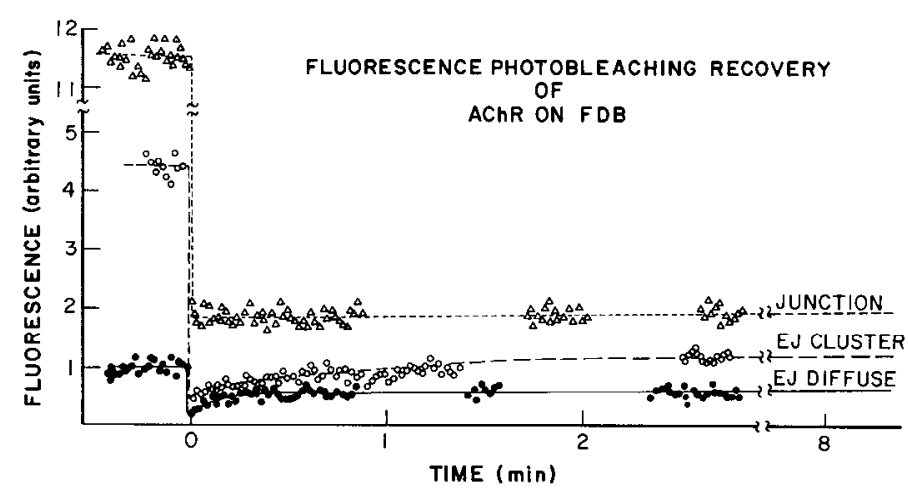

Figure 2. Typical FPR curves for R-BT-labeled AChR on FDB at a synaptic junction and at extrajunctional (EJ) clustered and nonclustered (diffuse) regions. The expected contributions of background and cellular autofluorescence have been subtracted as described under "Materials and Methods." The E.J diffuse region exhibits a weak fluorescence with a relatively rapid and substantial recovery; the EJ clustered region is brighter with a slower and less complete recovery; the junction shows no perceptible recovery.

TABLE I

Lateral diffusion coefficient $(D)$ and fractional mobility $(f)$ of $A C h R$ on $F D B$ and myotubes

Values are \pm SEM.

\begin{tabular}{lrcc} 
& $N$ & $D\left(10^{-10} \mathrm{~cm}^{2} / \mathrm{sec}\right)$ & $f$ \\
\hline FDB endplate & 6 & & $0.005 \pm 0.002$ \\
FDB diffuse & 14 & $0.54 \pm 0.04$ & $0.43 \pm 0.06$ \\
FDB cluster & 19 & $0.31 \pm 0.02$ & $0.15 \pm 0.01$ \\
Myotube & 17 & $1.0 \pm 0.1$ & $0.46 \pm 0.05$ \\
\hline
\end{tabular}



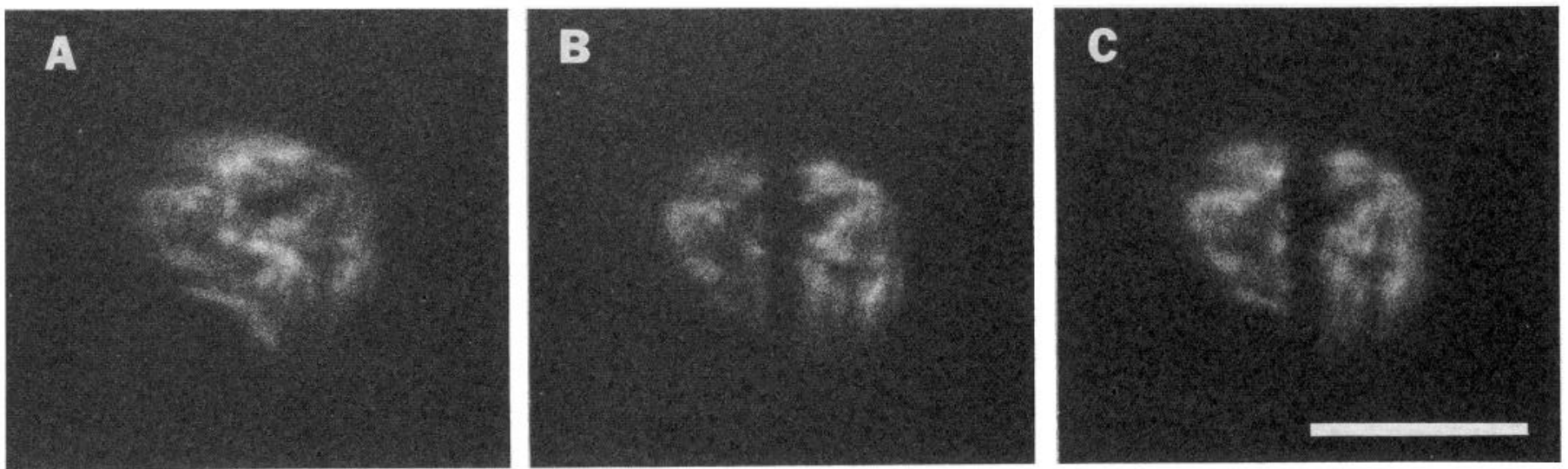

Figure 3. R-BT labeling of a junctional region on freshly dissociated FDB at the following times: $A$, before bleach; $B$, immediately after bleach by a focused Gaussian stripe; $C, 1 \mathrm{hr}$ after bleach. The dark bleached region is still distinct after $1 \mathrm{hr}$, thereby qualitatively demonstrating immobility of junctional AChR. The photographs were taken on TRI-X film through a $\times 40$ water immersion, 0.75-numerical aperture objective. Bar, $10 \mu \mathrm{m}$.

and diffusely distributed) and junctional $\mathrm{AChR}$ are shown in Figure 2. The results of the FPR experiments, presented in Table I, can be summarized as follows: $(i)$ as reported by others (Fambrough and Pagano, 1977; Axelrod et al., 1976b), junctional AChR on adult muscle fibers are essentially immobile with an average diffusion coefficient of $<10^{-12} \mathrm{~cm}^{2} / \mathrm{sec}$ (see Fig. 3); (ii) extrajunctional AChR are mobile; (iii) clustered extrajunctional AChR are less mobile than the diffusely distributed extrajunctional receptors; (iv) the fractional mobility of the diffusely distributed AChR on adult muscle fibers is similar to that of the diffusely distributed AChR on primary myotubes, but the diffusion coefficients of the mobile AChR on the former is somewhat lower than that of the latter. The molecular cause of the difference in diffusion rates in the two systems has not been investigated but conceivably may result from differences in cytoplasmic interactions, membrane environment, degree of AChR microclustering, or viscous drag of an extracellular matrix.

\section{Conclusion}

We find that the extrajunctional $\mathrm{AChR}$ on denervated adult muscle fibers differ greatly from junctional receptors on normally innervated muscle in their mobility within the plane of the membrane. The extrajunctional receptors are capable of lateral diffusion, while the junctional ones are positionally stable.

The difference in lateral mobility is in addition to the many other differences previously described. Extrajunctional AChR are less negatively charged than junctional ones (Brockes and Hall, 1975), have a longer mean open time (Dreyer et al., 1976; Sakman, 1978), and are less metabolically stable (Berg and Hall, 1975; Devreotes and Fambrough, 1976). Indeed, the extrajunctional $\mathrm{AChR}$ on denervated adult muscles are more similar to AChR on embryonic muscle than they are to the junctional $\mathrm{AChR}$ on normally innervated muscles. Both embryonic and denervated adult muscle exhibit AChR along their entire length (Bevan and Steinbach, 1977), exhibit extrajunctional clusters of AChR (Braithwaite and Harris, 1979), and exhibit diffusely distributed AChR which are laterally mobile while the clustered receptors are con- strained. On the basis of the available evidence, we consider it possible that denervation causes the muscle to revert to an embryonic state.

\section{References}

Axelrod, D. (1981) Crosslinkage and visualization of acetylcholine receptors on myotubes with biotinylated $\alpha$-bungarotoxin and fluorescent avidin. Proc. Natl. Acad. Sci. U. S. A. 77: 4823-4827.

Axelrod, D., D. E. Koppel, J. Schlessinger, E. Elson, and W. W. Webb (1976a) Mobility measurement by analysis of fluorescence photobleaching recovery kinetics. Biophys. J. 16 : $1055-1069$.

Axelrod, D., P. Ravdin, D. E. Koppel, J. Schlessinger, W. W. Webb, E. L. Nelson, and T. R. Podleski (1976b) Lateral motion of fluorescently labeled acetylcholine receptors in membranes of developing muscle fibers. Proc. Natl. Acad. Sci. U. S. A. 73: 4594-4598.

Bekoff, A., and W. Betz (1977) Properties of rat muscle fibers maintained in tissue culture. J. Physiol. 271: 537-547.

Berg, D. K., and Z. W. Hall (1975) Loss of $\alpha$-bungarotoxin from junctional and extra-junctional acetylcholine receptors in rat diaphragm muscle in vivo and in organ culture. J. Physiol. (Lond.) 252: 771-789.

Bevan, S., and J. H. Steinbach (1977) The distribution of $\alpha$ bungarotoxin binding sites on mammalian skeletal muscle developing in vivo. J. Physiol. 267: 195-213.

Bischoff, R. (1980) Plasticity of the myofiber-satellite cell complex in culture. In Plasticity of Muscle, D. Pette, ed., pp. 119-129, de Gruyter and Co., Berlin.

Braithwaite, A. W., and A. J. Harris (1979) Neural influence on acetylcholine receptor clusters in embryonic development of skeletal muscles. Nature 279: 549-551.

Brockes, J. P., and Z. W. Hall (1975) Acetylcholine receptors in normal and denervated rat diaphragm muscle. II. Comparison of junctional and extra-junctional receptors. Biochemistry 14: 2100-2106.

Brockes, J. P., and Z. W. Hall (1976) Synthesis of the acetylcholine receptor by cultured chick myotubes and denervated mouse extensor digitorum longus muscles. Proc. Natl. Acad. Sci. U. S. A. 73: 161-164.

Devreotes, P. N., and D. M. Fambrough (1975) Acetylcholine receptor turnover in membranes of developing muscle fibers. J. Cell Biol. 65: 335-358.

Devreotes, P. N., and D. M. Fambrough (1976) Synthesis of the acetylcholine receptor by cultured chick myotubes and 
denervated mouse extensor digitorum longus muscles. Proc. Natl. Acad. Sci. U. S. A. 73: 161-164.

Dreyer, F., K. D. Miller, K. Peper, and R. Sterz (1976). The M. omohyoideus of the mouse as a convenient mammalian muscle preparation: A study of junctional and extra-junctional acetylcholine receptors by noise analysis. Pflugers Arch. 367: $115-122$.

Fambrough, D. M., and R. E. Pagano (1977) Positional stability of acetylcholine receptors at the neuromuscular junction. Carnegie Inst. Wash. Yearb. 76: 28-29.

Feldman, E. L., D. Axelrod, M. Schwartz, A. M. Heacock, and B. W. Agranoff (1981) Studies of the localization of newly added membrane in growing neurites. J. Neurobiol. 12: 591598.

Jacobson, K., E. Elson, D. Koppel, and W. Webb (1983) International workshop on the application of fluorescence photobleaching techniques to problems in cell biology. Fed. Proc. 42: $72-79$.

Ko, P. K., M. J. Anderson, and M. W. Cohen (1977) Denervated skeletal muscle fihers develop discrete patches of high acetylcholine receptor density. Science 196: 540-542.

Ravdin, P., and D. Axelrod (1977) Fluorescent tetramethyl rhodamine derivatives of $\alpha$-bungarotoxin: Preparation, separation and characterization. Anal. Biochem. 80: 585-592, and correction (1977) 83: 336.

Sakman, B. (1978) Acetylcholine-induced ionic channels in rat skeletal muscle. Fed. Proc. 37: 2654-2659.

Stya, M. (1983) Mobility of acetylcholine receptors in muscle cell membranes. Ph.D. Dissertation, University of Michigan, appendix. Xerox University Microfilms, Ann Arbor, MI.

Tipnis, U. R., and S. K. Malhotra (1979) Bungarotoxin binding sites (acetylcholine receptors) in denervated mammalian sarcolemma. J. Supramol. Struct. Cell Biochem. 12: 321-334.

Young, S.H., and Poo, M-M. (1983) Rapid lateral diffusion of extrajunctional acetylcholine receptors in the developing muscle membrane of Xenopus tadpole. J. Neurosci. 3: 225231. 